Check for updates

Cite this: RSC Adv., 2018, 8, 26682

Received 28th February 2018

Accepted 20th July 2018

DOI: $10.1039 / c 8 r a 01781 f$

rsc.li/rsc-advances

\section{Enrichment of soybean dietary fiber and protein fortified rice grain by dry flour extrusion cooking: the physicochemical, pasting, taste, palatability, cooking and starch digestibility properties}

\author{
Xia Liu, (D) *a Jiafeng Zhao, ${ }^{a}$ Xin Zhang, ${ }^{b}$ Yuan Li, ${ }^{a}$ Juan Zhao, ${ }^{a}$ Tongtong Li, ${ }^{a}$ \\ Boyang Zhou, ${ }^{a}$ Hongyuan Yang ${ }^{a}$ and Liping Qiao ${ }^{a}$
}

\begin{abstract}
With the prevalence of chronic conditions in patients due to a dietary imbalance, the demand for inexpensive, nutritious and high dietary fiber extruded rice is increasing rapidly. However, the factors of quality and bioavailability are still the major constraints to its development. In this study, soybean dietary fiber (DF) and protein fortified rice grain were prepared via dry flour extrusion processing. The results showed that the extruded rice had a similar density to that of natural rice and a significantly lower whiteness degree and transparency. Notably, the cooking texture and palatability of extruded rice were affected by the added amount of DF, resulting in rice with a taste value close to 70 in DF 6-9\% $(\mathrm{w} / \mathrm{W})$ samples. The pasting properties, microstructure, and molecular interactions according to RVA, SEM and FTIR analyses, respectively, were also significantly affected by the DF content. The soluble dietary fiber was significantly increased from $0.0021 \mathrm{~g} \mathrm{~g}^{-1}$ to $0.216 \mathrm{~g} \mathrm{~g}^{-1}$ in extruded rice. Importantly, the starch digestibility in vitro showed significantly lower readily digestible starch (RDS) and higher resistant starch (RS) in DF 6-15\% (w/w) extruded rice than in natural rice and DF-0 rice, respectively. The glycemic index (Gl) was reduced in DF $>6 \%$. In this study, we provide a new high dietary fiber extruded rice product with good texture and palatability, and we reveal the effect of DF on the extruded rice properties.
\end{abstract}

\section{Introduction}

Dietary fiber (DF) intake is a key component in healthy eating due to its health benefits. A diet high in dietary fiber is protective against many chronic conditions, such as obesity, heart disease, diabetes, colon cancer, kidney disease, and digestive disorders, including irritable bowel syndrome. ${ }^{1-5}$ Fiber plays an important role in clearing the body of toxins, helping to reduce inflammation and clearing the arteries as it removes waste and pathogens from the body. ${ }^{6,7}$ A functional foods-based fiber fortified diet would be a novel dietary approach for avoiding chronic diseases caused by malnutrition.

The daily fiber requirement for adults is $38 \mathrm{~g}$ for males and $25 \mathrm{~g}$ for females. Usually, grains and cereal-based products are the basic sources providing energy and carbohydrates in human diets. Polished white rice, the traditional and most commonly consumed form of rice grain, lacks fiber, vitamins and mineral nutrients due to the removal of the husk, bran, and germ. However, white rice is

\footnotetext{
${ }^{a}$ State Key Laboratory of Food Nutrition and Safety, Ministry of Education of China, College of Food Engineering and Biotechnology, Tianjin University of Science \& Technology, No. 29, 13th Street, TEDA, Tianjin 300457, China. E-mail: liuxia831930@163.com

${ }^{b}$ College of Agronomy \& Resources and Environment, Tianjin Agricultural University, Tianjin 300384, China
}

perceived to be more palatable than brown rice. Thus, delicious and nutrient-rich rice derived from new processing methods is important. To compensate for the lack of fiber and the preference for white rice, brown rice and wild rice have been advocated as healthier alternatives since the 19th century.,

Extrusion cooking is a practical technology that converts raw materials into a products with a desired shape and form by forcing the material through a small opening using pressure and thermal energy. Extrusion cooking is a promising technology for various food products, and it has been applied to improve the quality and nutrition of many processed foods, such as snacks, cereal fermented wines, noodles, crisps, baby foods and sweets. ${ }^{1,9-12}$ A large number of studies on snacks, noodles and crisps prepared by the extrusion method have reported the fortification formulae, technological parameters, and nutritional and functional properties of these foods. ${ }^{13-20}$ Importantly, extrusion processing can increase the soluble dietary fiber (SDF) content in many different sources, which is important due to its implications for improving health and biological functions. ${ }^{\mathbf{1 0 2 1 - 2 3}}$ The functionality and digestibility of extruded cereal grain flour can be effectively regulated by macromolecular degradation during extrusion. ${ }^{24}$

However, less information is available on the effect of fiber in extruded rice grain staples on the physicochemical, pasting, 
taste, palatability, cooking and starch digestibility properties. The quality of extruded rice is difficult to control regarding its expansion and compactness, which are typically the main limiting factors for extruded rice development.

It is well known that the formulae used to fortify extrusion cooked foods play pivotal roles not only in the prevention of deficiencies and disorders but also in imparting structure, texture, mouth feel, bulk, and many other characteristics to the food..$^{25,26}$ In addition, changes in the physicochemical characteristics occur when the raw material ingredients are dispersed, homogenized and structurally reengineered under the thermomechanical and mechanical energies of the extrusion cooking process. ${ }^{27-29}$ Milled rice has a high content of carbohydrates and a low content of DF and protein. Nutrition-rich rice grains containing a protein and fiber combination are important for a balanced diet. Therefore, the purpose of this study was to produce protein- and DF-rich extruded rice with acceptable physical and cooking characteristics and reveal the regulatory behaviors of dietary fiber on starch digestibility, pasting, taste and palatability properties using extrusion processing. To determine the technical feasibility, various formulations with DF contents of $0 \%, 3 \%, 6 \%, 9 \%, 12 \%$ and $15 \%(\mathrm{w} / \mathrm{w})$ were prepared to produce nutrition fortified rice grain through extrusion. The effects of soybean fiber on physicochemical properties such as bulk density, whiteness, transparency, taste, texture and cooking quality were investigated. The starch digestibility in vitro and the glycemic index (GI) were also evaluated.

\section{Materials and methods}

\subsection{Materials}

Rice flour was purchased from the Tianjin Baiaotai Technology Development Co. Ltd., China, with a protein content of $7.5 \%$, a total starch content of $71.92 \%$, and a total starch amylose to amylopectin ratio of $24.37: 75.63$. Soybean protein powder (with $81 \%$ protein and $15 \%$ fat) was purchased from the Tianjin Baiaotai Technology Development Co., Ltd., China. Soybean dietary fiber was purchased from the Wuhan Jiangmin Huatai Pharmaceutical Chemical Co., Ltd., China with 5\% soluble dietary fiber and 55\% insoluble dietary fiber.

\subsection{Preparation of samples and the extrusion process parameters}

All powders were passed through an 80-mesh sieve, and the rice flour, soybean protein powder and dietary fiber from soybeans were blended in ratios of $92: 8: 0$ (designated as dietary fiber $0.00 \%$ ), $89: 8: 3$ (dietary fiber $3.00 \%$ ), $86: 8: 6$ (dietary fiber $6.00 \%$ ), $83: 8: 9$ (dietary fiber $9.00 \%$ ), $80: 8: 12$ (dietary fiber $12.00 \%$ ) and $77: 8: 15$ (dietary fiber $15.00 \%$ ) to prepare samples DF-0, DF-3, DF-6, DF-9, DF-12, DF-15, respectively. Natural long grain rice was used as the control (CK).

The powders and water $(74: 26, \mathrm{w} / \mathrm{w})$ were stirred until well blended. The powders were kept for 30-60 $\mathrm{min}$ at room temperature for moisture equilibration. Next, the powders were extruded in a twin-screw extruder (DS32-VII, Jinan Saibainuo Technology Development Co., Ltd., China). The screw of the extruder was divided into four zones with temperatures of $90{ }^{\circ} \mathrm{C}$ at zone $1,100{ }^{\circ} \mathrm{C}$ at zone $2,110{ }^{\circ} \mathrm{C}$ at zone 3 and $60^{\circ} \mathrm{C}$ at zone 4 . The screw speed was $150 \mathrm{rpm}$. Finally, the extruded rice was dried at $50{ }^{\circ} \mathrm{C}$ for $5 \mathrm{~h}$, cooled at room temperature for $8 \mathrm{~h}$ and sealed in polyethylene bags for further analysis.

\subsection{Bulk density, whiteness and transparency}

Bulk density is a vital physical property. The bulk density was described by the sample mass divided by the sample volume..$^{30,31}$ Briefly, the bulk density of extruded rice was determined using a volumetric displacement procedure. Edible oil was used as a displacement medium. Five measurements were performed for each dietary fiber content of the extruded rice. Approximately $1 \mathrm{~g}$ extruded rice was selected, and the total weight was recorded $(m)$. Next, $4 \mathrm{~mL}$ edible oil $\left(V_{0}\right)$ was poured into a $10 \mathrm{~mL}$ graduated cylinder. The extruded rice was placed in the same graduated cylinder, and the volume $\left(V_{1}\right)$ was recorded. The bulk density of the extruded rice was calculated as

$$
\rho\left(\mathrm{g} \mathrm{mL}^{-1}\right)=\frac{m}{V_{1}-V_{0}}
$$

The whiteness and transparency were measured using a Satake MM1D rice meter (brown rice model).

\subsection{Pasting characteristics}

The pasting properties were measured with a Rapid Visco Analyzer model 3-D RVA (Newport Scientific, Sydney, Australia). Rice flour ( $3 \mathrm{~g}$ of each sample, $12 \% \mathrm{~m} . \mathrm{b}$.) was weighed directly into the aluminium RVA canister, and $25 \mathrm{~mL}$ of distilled water was added and mixed with the rice flour. The RVA test profile was adopted from the method of Elaine T. Champagne et al. ${ }^{32}$ The sample was held at $50{ }^{\circ} \mathrm{C}$ for $1 \mathrm{~min}$, heated to $95^{\circ} \mathrm{C}$ for $2.5 \mathrm{~min}$, cooled to $50{ }^{\circ} \mathrm{C}$ at a rate of $12{ }^{\circ} \mathrm{C} \mathrm{min}{ }^{-1}$ and held at $50{ }^{\circ} \mathrm{C}$ for $2.5 \mathrm{~min}$. The rotating speed of the paddle was kept at $160 \mathrm{rpm}$ throughout the run, except for the first $10 \mathrm{~s}$ when the paddle speed was $960 \mathrm{rpm}$. The viscosity was measured in Rapid Visco Units (RVU). All measurements were replicated three times.

\subsection{Taste and palatability properties}

The assays for the taste and palatability characteristics in nutrition fortified rice were performed using a SATAKE rice taste analyzer ${ }^{33}$ The extruded rice was dried to a final moisture content of $14.5 \%$. For each sample, $30 \mathrm{~g}$ of nutrition fortified rice was washed with flowing water for $30 \mathrm{~s}$ and soaked in $40.5 \mathrm{~g}$ water in a stainless steel tin at room temperature for $30 \mathrm{~min}$. The tin was tightly sealed and transferred to an electric rice cooker for $40 \mathrm{~min}$. Next, the cooker was switched from the "cook" to the "warm" setting, and the warm setting was maintained for several minutes. Then, $8 \mathrm{~g}$ of cooked extruded rice was transferred to a mold to form a cooked rice cake from the middle of the tin. The hardness, stickiness, degree of balance, spring, appearance and taste value were evaluated using an STA1A rice taste analyzer.

\subsection{Scanning electron microscopy (SEM) analysis}

For scanning electron microscopy (SEM) observation, extruded rice grains were broken transversely; the pieces were mounted 
onto $12 \mathrm{~mm}$ aluminium stubs and sputtered with gold on a BioRad Polaron sputter coater. The samples were viewed under an S-2500 Hitachi SEM and examined using SEM at an accelerating voltage of $20 \mathrm{kV}$ (Quanta 200, FEI). The diameters of the starch granules were estimated on the basis of the scale bar provided on the captured sample.

\subsection{Fourier transform infrared (FTIR) analysis}

Changes in the molecular structure of extruded rice with varying DF were comparatively investigated using Fourier transform infrared spectroscopy (FTIR). The sample (1 mg) was mixed with $150 \mathrm{mg}$ of $\mathrm{KBr}$ and pressed into a pellet according to the published method. ${ }^{34}$ FTIR spectra were recorded at wave numbers from $4000 \mathrm{~cm}^{-1}$ to $400 \mathrm{~cm}^{-1}$ with a Thermo Nicolet Fourier transform infrared spectrometer equipped with a DTGS $\mathrm{KBr}$ detector (Thermo Nicolet Corporation, USA). Each sample was subjected to 32 scans per sample at a $4 \mathrm{~cm}^{-1}$ resolution.

\subsection{Dietary fiber content}

The total dietary fiber (TDF) and soluble dietary fiber (SDF) of nutrition fortified rice grain were determined using an enzymatic-gravimetric method with a fiber assay kit (Megazyme K-TDFR, Wicklow, Ireland). Briefly, $1 \mathrm{~g}$ of sample suspended in Mes-Tris buffer was sequentially digested using heat stable $\alpha$ amylase for $35 \mathrm{~min}$ in a boiling water bath; then, protease and amyloglucosidase were added, and the mixture was held for $30 \mathrm{~min}$ at $60{ }^{\circ} \mathrm{C}$. After filtration, the SDF in the filtrate was precipitated with ethanol and filtered. The precipitate, referred to as SDF, was dried at $105{ }^{\circ} \mathrm{C}$ and weighed. The SDF content was corrected for residual protein and ash content. The TDF content was obtained using the same procedure as that for SDF without filtration and with direct precipitation.

\subsection{Rice cooking properties}

2.9.1. Rice cooking. A weight of $2.5 \mathrm{~g}$ extruded rice was combined with $25 \mathrm{~mL}$ of distilled water in a wide-mouth glass bottle. The bottle was immersed in a boiling water bath for $20 \mathrm{~min}$, and then it was placed in an ice bath for $5 \mathrm{~min}$. The water uptake capacity of the cooked extruded rice and the solids content, $\mathrm{pH}$ and turbidity of the residual cooking water were analyzed.

2.9.2. Water uptake capacity of the cooked rice. The water uptake capacity of the cooked rice was calculated from the difference between the total cooking water and the residual cooking water after the cooking process and was expressed as $\mathrm{mL} \mathrm{g}^{-1}$ grain. The residual cooking water was used for subsequent analysis of the solids content, $\mathrm{pH}$ and turbidity.

2.9.3. $\mathrm{pH}$ of the residual cooking water. The $\mathrm{pH}$ of the residual cooking water was determined using a digital $\mathrm{pH}$ meter (FB20, Ohaus Instruments (Shanghai) Co., Ltd.) at room temperature $\left(20^{\circ} \mathrm{C}\right)$.

2.9.4. Solids content of the residual cooking water. The solids content of the residual cooking water was measured by weighing the dried $10 \mathrm{~mL}$ aliquot of residual cooking water at $110{ }^{\circ} \mathrm{C}$ and was expressed as $\mathrm{mg} \mathrm{mL}^{-1}$.
2.9.5. Turbidity of the residual cooking water. To measure the turbidity of the residual cooking water, the water was left to stand overnight at room temperature $\left(20^{\circ} \mathrm{C}\right)$ to allow settling of the large particles in the water. The aqueous layer was used to determine the turbidity, which was measured using a UV/VIS spectrophotometer (T6, New Century, General Analysis Beijing General Instrument Co., Ltd.). The turbidity was expressed as the absorbance at $600 \mathrm{~nm}$.

\subsection{Starch digestibility in vitro}

In vitro starch digestibility was analyzed according the method reported previously, with some modifications. ${ }^{35,36}$ Briefly, a $10 \mathrm{~g}$ rice sample was added to a wide-mouth glass bottle containing $12 \mathrm{~mL}$ of water. Next, the bottle with rice was steamed for $20 \mathrm{~min}$ in a steamer. Then, aliquots of the cooked rice $(2 \mathrm{~g})$ with $20 \mathrm{~mL}$ of sodium acetate (0.2 M, pH 5.2) and seven glass balls $(10 \mathrm{~mm}$ in diameter) were used for simulated intestinal peristalsis.

Next, $1 \mathrm{~mL}$ amyloglucosidase $\left(100000 \mathrm{U} \mathrm{mL}^{-1}\right.$, Shanghai Yuan Ye Biological Technology Co., Ltd.) was added to $2 \mathrm{~mL}$ deionized water, and $3 \mathrm{~g}$ porcine pancreatic $\alpha$-amylase (13 U $\mathrm{mg}^{-1}$, Shanghai Yuan Ye Biological Technology Co., Ltd.) was dispersed in $15 \mathrm{~mL}$ water and centrifuged for $10 \mathrm{~min}$ at $2500 \mathrm{rpm} ; 12 \mathrm{~mL}$ of supernatant was collected. This supernatant was mixed with $1 \mathrm{~mL}$ of diluted amyloglucosidase to serve as the enzyme solution. The solution was freshly prepared for the digestion analysis.

Aliquots of sodium acetate $(20 \mathrm{~mL}, 0.2 \mathrm{M})$ were added to the simulated digested samples ( $2 \mathrm{~g}$ ) in Erlenmeyer flasks. Seven glass balls (10 $\mathrm{mm}$ in diameter) and $2 \mathrm{~mL}$ of enzyme solution were added to each Erlenmeyer flask followed by incubation in a shaking water bath at $37^{\circ} \mathrm{C}$ with agitation $(170 \mathrm{rpm})$. Aliquots $(1 \mathrm{~mL})$ were taken at intervals and mixed with $5 \mathrm{~mL}$ of ethanol, and the glucose contents in the mixture were measured using glucose oxidase and peroxidase assay kits (Shanghai Rongsheng Bio-Pharmaceutical Co., Ltd.). The total starch content was measured according to Englyst et al. ${ }^{35}$

The starch classification based on its digestibility was readily digestible starch (RDS), as this was the starch that was hydrolyzed within 20 min of incubation; resistant starch (RS), was the starch not hydrolyzed with $120 \mathrm{~min}$; and slowly digestible starch (SDS) was the starch digested during the period between 20 and $120 \mathrm{~min}$.

\subsection{Estimated glycemic index (GI)}

Using the hydrolysis curve (0-180 $\mathrm{min})$, the hydrolysis index (HI) was calculated as the percentage of total glucose released from the sample compared to that released from white bread. ${ }^{37,38}$ The glycemic indices of the samples were estimated according to the equation proposed by Goñi et al. GI $=39.71+$ $0.549 \mathrm{HI}^{37}$

\subsection{Statistical analysis}

All experiments were conducted at least twice. Data were analyzed using SPSS statistical software (Version 20.0, SPSS Inc., Chicago, IL, USA), with one-way-analysis of variance (ANOVA) 
followed by the least significant difference (LSD) test and Duncan's test $(p<0.05)$. The results are shown as the means and standard deviations (SDs). SPSS was used to verify significant differences among synthetic rice types with different soybean dietary fiber contents.

\section{Results and discussion}

\subsection{Effect of soybean dietary fiber on the physical characteristics of extruded rice grain}

The appropriate extrusion process parameters for the production of extruded rice grain for our materials, such as temperature, feed moisture, and screw speed, were in accordance with the findings of our previous research results. ${ }^{39}$ Table 1 summarizes several physical characteristics of extruded rice grain, revealing the impact of different added soybean DF flour levels. As expected, the extruded rice grains have a significantly high density equivalent to natural rice grains. Furthermore, the levels of DF contents had no effect on the density of the extruded rice grains. However, the DF contents negatively influenced grain whiteness and transparency (Table 1). The whiteness degree and transparency values obviously decreased with increasing soybean DF flour levels.

The extruded grain density is an appropriate target to evaluate the porosity of produce, which influences water-absorbing properties and texture tightness. The moderate density provided the rice with a good hardness, similar to that of natural rice grain. The lower whiteness and transparency gave the extruded rice an appearance similar to that of waxy rice in the DF0 treatment, but a darker color was exhibited with a high DF, similar to that with high protein contents in extruded products. ${ }^{40}$

Fig. 1 and 2 show the appearance and microstructure of the extruded rice. There were significant color differences among different DF extruded rice types, and these differences decreased as the DF content increased. The SEM results showed a significantly hard shell in extruded rice with DF-0 and DF-3, whereas a relatively loose microstructure was observed in DF0 and DF-3. Meanwhile, with increasing DF contents, the structure of extruded rice lost the hard shell, and the inner structure became tight (Fig. 2A1-F1). This phenomenon may be because the branching structure of the dietary fiber reduces the

Table 1 Effect of DF content on some physical characteristics of extruded rice grain ${ }^{a}$

\begin{tabular}{llll}
\hline DF content (\%) & Density $\left(\mathrm{g} \mathrm{mL}^{-1}\right)$ & Whiteness degree & Transparency \\
\hline CK & $0.3359 \pm 0.0942^{\mathrm{a}}$ & $41.10 \pm 0.10^{\mathrm{a}}$ & $3.88 \pm 0.10^{\mathrm{a}}$ \\
DF-0 & $0.3322 \pm 0.0987^{\mathrm{a}}$ & $19.40 \pm 0.10^{\mathrm{b}}$ & $2.10 \pm 0.10^{\mathrm{b}}$ \\
DF-3 & $0.3359 \pm 0.1028^{\mathrm{a}}$ & $18.80 \pm 0.20^{\mathrm{b}}$ & $1.72 \pm 0.10^{\mathrm{c}}$ \\
DF-6 & $0.3325 \pm 0.0972^{\mathrm{a}}$ & $14.90 \pm 0.10^{\mathrm{c}}$ & $1.50 \pm 0.10^{\mathrm{c}}$ \\
DF-9 & $0.3374 \pm 0.0886^{\mathrm{a}}$ & $14.10 \pm 0.10^{\mathrm{d}}$ & $1.48 \pm 0.10^{\mathrm{d}}$ \\
DF-12 & $0.3412 \pm 0.0914^{\mathrm{a}}$ & $13.93 \pm 0.15^{\mathrm{e}}$ & $1.08 \pm 0.06^{\mathrm{e}}$ \\
DF-15 & $0.3357 \pm 0.0799^{\mathrm{a}}$ & $12.73 \pm 0.49^{\mathrm{f}}$ & $0.94 \pm 0.01^{\mathrm{f}}$
\end{tabular}

${ }^{a}$ All the values are the mean \pm SD. Values with different letters within a column are significantly different at $p<0.05$ as evaluated by Tukey's test to analyze the different soybean DF contents and the CK (a natural rice) in the same column.

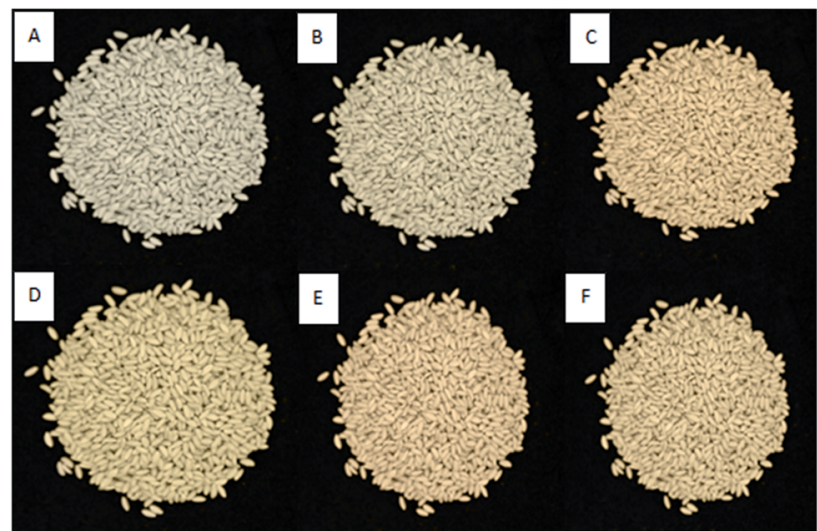

Fig. 1 Appearance of extruded rice grain obtained at different soybean DF contents (\%). (A) Extruded rice grain of 0\% soybean DF content; (B) extruded rice grain of $3 \%$ soybean DF content; (C) extruded rice grain of $6 \%$ soybean DF content; (D) extruded rice grain of $9 \%$ soybean DF content; (E) extruded rice grain of $12 \%$ soybean DF content; (F), extruded rice grain of $15 \%$ soybean DF content.

interactions of extruded rice starch granules due to the obvious DF embedded in the grain. From Fig. 2A2-F2, the starch granule crystal structure decreased and then increased with increasing DF contents, with DF-9 extruded rice having the least crystal structure characteristics. This result may be because dietary fiber as the macromolecule facilitated the dispersion of small starch granules, thus causing the starch granules to more homogenized and cohesive during the high-temperature and high-pressure extrusion process.

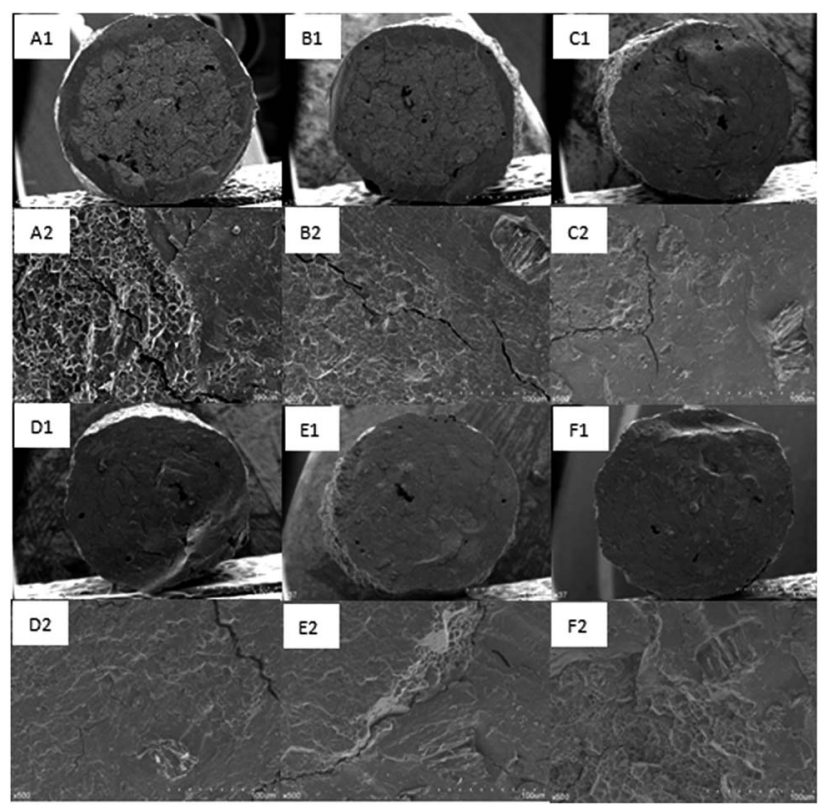

Fig. 2 SEM images of extruded rice grain obtained at different soybean DF contents (\%). (A) Extruded rice grain of 0\% soybean DF content; (B) extruded rice grain of $3 \%$ soybean DF content; (C) extruded rice grain of $6 \%$ soybean DF content; (D) extruded rice grain of $9 \%$ soybean DF content; (E) extruded rice grain of $12 \%$ soybean DF content; (F) extruded rice grain of $15 \%$ soybean DF content. A1-F1 are cross-section images of the dry extrusion rice. A2-F2 are 500-fold magnified images of the previous rice cross sections. 


\subsection{Taste and palatability properties of cooked extruded rice grain}

Taste and palatability are important and direct indices for estimating the eating quality of the extruded rice grain using a taste meter compared to normal sensory evaluation. In this study, we showed the taste and palatability for various DF levels of extruded rice grain in Table 2 in which the hardness of cooked extruded rice was significantly lower than that of natural milled rice, likely due to a change in the interaction of starch granules and a reordering of starch molecules to form a new structure during gelatinization. The hardness of extruded rice grain initially significantly increased and then decreased with increasing dietary fiber contents. The extruded rice with DF-6 had the greatest hardness, and the viscosity of the extruded rice steadily increased and then decreased; DF-6 and DF-9 had a higher viscosity than that of the other extruded rice samples and that of natural long-grain CK rice. Meanwhile, there was a higher stretch value in DF-0, and the stretchability decreased with increasing dietary fiber additions, while the stretch value of extruded rice grains with a higher DF increased slightly, with a turning point at DF-6. The stretch values of DF-6 and DF-9 were considerably closer to that of the natural CK rice. These results agree with the texture property changes in fiber fortified rice with dietary rice bran. ${ }^{\mathbf{4 1}}$

However, the appearance of cooked extruded rice with DF was less appealing than that of natural CK rice due to the lower whiteness degree and transparency. Balance values represent the ratio of viscosity and hardness of the cooked rice; higher values indicate softer rice. The balance values of cooked extruded rice were significantly higher than those of natural CK rice, which is generally attributed to glutinous qualities, elasticity and hardness. When the DF content was $9 \%$, the balance value was highest. We observed that the extruded rice had a notably good taste value, especially for DF-9. The taste of natural rice is typically classified into four grades according to the taste values of $>70,60-70,50-60$ and $<50$ corresponding to super taste, good taste, medium taste and poor taste. ${ }^{42}$ Almost all of the extruded rice with DF reached a score of nearly 70 , which is favorable for a staple food.

\subsection{Pasting properties}

RVA studies are used extensively to characterize the pasting properties of starch in grains and processed foods. ${ }^{32,43,44}$ Table 3 shows the RVA values of different DF levels of extruded rice grain. The peak viscosity of the extruded rice was $82.89 \pm 0.90 \mathrm{RVU}$, $78.50 \pm 1.04$ RVU, $77.03 \pm 0.85$ RVU, $74.75 \pm 0.79$ RVU, $75.89 \pm$ 1.25 RVU and 70.38 \pm 0.62 RVU in the DF-0, DF-3, DF-6, DF-9, DF12 and DF-15 samples, respectively, which are significantly lower than that of natural rice (293.60 $\pm 7.04 \mathrm{RVU})$. With increasing DF addition, the peak viscosity significantly decreased, possibly because the dietary fiber impeded swelling, perhaps by leaching into the continuous, viscous phase of the paste and constraining granule expansion. ${ }^{43}$ The peak viscosity, trough, breakdown and final viscosity all decreased with increasing DF contents. The setback value of the RVA profile with different values of peak viscosity and trough paste viscosity was closely related to the rice texture, and the setback values were negative in the extruded rice with DF. The differences in peak time and pasting temperature were both lower with increasing DF. Compared to natural rice, all extruded rice samples had significantly lower peak times and higher pasting temperatures. Briefly, the extruded rice showed lower pasting properties than those of natural rice, and the results agreed with the literature. ${ }^{45}$

\subsection{Cooking properties of extruded rice with different DF contents}

The properties of the residual cooking water and water uptake of rice grain are shown in Table 4 . The extruded rice showed lower water uptake, which suggested that hydration of extruded rice grain is more resistant than natural rice grains to hydrothermal disruption. The properties of residual cooking water differed significantly between the natural rice and extruded rice (Table 3). Extruded rice had significantly higher $(p<0.05)$ solids content of residual cooking water and a lower turbidity of residual cooking water $(p<0.05)$ than those of natural rice because the extruded rice grain components were easier to extract. The high solids content in the cooking water indicated a greater cooking loss due to leaching of gelatinized starch/fiber particles into the cooking water. The extruded rice with DF-9 had the most turbid residual cooking water, possibly because the structure of the fiber was modified due to the high-temperature heating and the high pressure of the extrusion process. ${ }^{46}$

The $\mathrm{pH}$ of the residual cooking water of extruded rice decreased with increasing DF addition. These differences are consistent with the inhibition of the leaching of rice components, particularly with increasing DF content.

Table 2 Taste and palatability properties of extruded rice grains fortified with different levels of DF

\begin{tabular}{|c|c|c|c|c|c|c|}
\hline DF content (\%) & Hardness & Viscosity & Balance & Stretch & Taste & Appearance \\
\hline CK & $4.13 \pm 0.11^{\mathrm{a}}$ & $0.41 \pm 0.01^{\mathrm{c}, \mathrm{d}}$ & $0.09 \pm 0.01^{\mathrm{d}}$ & $0.74 \pm 0.01^{\mathrm{e}}$ & $71.33 \pm 0.58^{\mathrm{b}}$ & $0.623 \pm 0.006^{\mathrm{a}}$ \\
\hline 0 & $1.15 \pm 0.08^{\mathrm{d}}$ & $0.35 \pm 0.00^{\mathrm{d}}$ & $0.30 \pm 0.02^{\mathrm{b}, \mathrm{c}}$ & $0.89 \pm 0.01^{\mathrm{a}}$ & $69.00 \pm 1.00^{c}$ & $0.597 \pm 0.006^{\mathrm{b}}$ \\
\hline 3 & $1.53 \pm 0.02^{c}$ & $0.41 \pm 0.04^{\mathrm{c}, \mathrm{d}}$ & $0.27 \pm 0.02^{\mathrm{c}}$ & $0.78 \pm 0.02^{\mathrm{c}, \mathrm{d}}$ & $69.00 \pm 1.00^{c}$ & $0.590 \pm 0.010^{\mathrm{b}, \mathrm{c}, \mathrm{d}}$ \\
\hline 6 & $2.05 \pm 0.28^{\mathrm{b}}$ & $0.55 \pm 0.03^{\mathrm{a}, \mathrm{b}}$ & $0.27 \pm 0.02^{c}$ & $0.76 \pm 0.02^{\mathrm{c}, \mathrm{d}, \mathrm{e}}$ & $69.67 \pm 2.08^{\mathrm{b}, \mathrm{c}}$ & $0.580 \pm 0.000^{\mathrm{d}}$ \\
\hline 9 & $1.64 \pm 0.13^{c}$ & $0.57 \pm 0.04^{\mathrm{a}}$ & $0.35 \pm 0.01^{\mathrm{a}}$ & $0.75 \pm 0.02^{\mathrm{d}, \mathrm{e}}$ & $69.00 \pm 1.00^{c}$ & $0.593 \pm 0.006^{\mathrm{b}, \mathrm{c}}$ \\
\hline 12 & $1.56 \pm 0.04^{\mathrm{c}}$ & $0.48 \pm 0.04^{\mathrm{b}, \mathrm{c}}$ & $0.31 \pm 0.02^{\mathrm{b}}$ & $0.79 \pm 0.03^{c}$ & $69.00 \pm 0.00^{c}$ & $0.597 \pm 0.006^{\mathrm{b}}$ \\
\hline 15 & $1.25 \pm 0.12^{\mathrm{d}}$ & $0.42 \pm 0.08^{\mathrm{c}, \mathrm{d}}$ & $0.33 \pm 0.03^{\mathrm{a}, \mathrm{b}}$ & $0.83 \pm 0.01^{\mathrm{b}}$ & $77.33 \pm 0.58^{\mathrm{a}}$ & $0.583 \pm 0.006^{\mathrm{c}, \mathrm{d}}$ \\
\hline
\end{tabular}

${ }^{a}$ All the values are the mean $\pm \mathrm{SD}$. Values with different letters within a column are significantly different at $p<0.05$ as evaluated by Tukey's test to analyze the different soybean DF contents and the CK (a natural rice) in the same column. 
Table 3 Pasting properties of extruded rice grains fortified with different levels of $\mathrm{DF}^{a}$

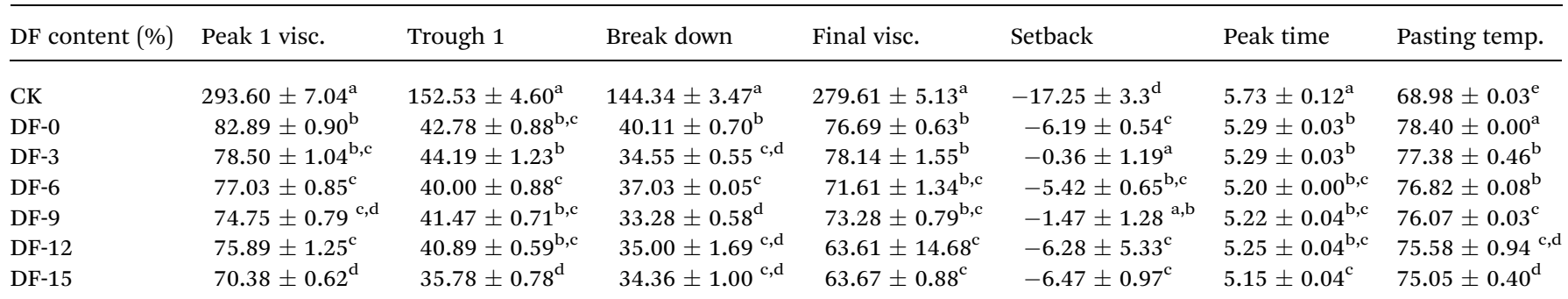

${ }^{a}$ All the values are the mean \pm SD. Values with different letters within a column are significantly different at $p<0.05$ as evaluated by Tukey's test to analyze the different soybean DF contents and the CK (a natural rice) in the same column.

Table 4 Cooking properties of extruded rice grains fortified with $\mathrm{DF}^{a}$

\begin{tabular}{lllll}
\hline Sample & $\begin{array}{l}\text { Water uptake } \\
\text { capacity }\left(\mathrm{mL} \mathrm{g}^{-1}\right)\end{array}$ & $\begin{array}{l}\text { Solids content of residual } \\
\text { cooking water }\left(\mathrm{g} \mathrm{g}^{-1}\right)\end{array}$ & $\begin{array}{l}\text { pH of residual } \\
\text { cooking water }(-)\end{array}$ & $\begin{array}{l}\text { Turbidity of residual } \\
\text { cooking water }(\text { OD) }\end{array}$ \\
\hline CK & $3.732 \pm 0.037^{\mathrm{a}}$ & $0.132 \pm 0.327^{\mathrm{d}}$ & $6.58 \pm 0.0208^{\mathrm{c}}$ & $0.443 \pm 0.0117^{\mathrm{a}}$ \\
DF-0 & $1.951 \pm 0.300^{\mathrm{c}}$ & $0.258 \pm 0.397^{\mathrm{c}}$ & $6.87 \pm 0.0529^{\mathrm{a}}$ & $0.180 \pm 0.0217^{\mathrm{c}}$ \\
DF-3 & $1.732 \pm 0.275^{\mathrm{c}}$ & $0.260 \pm 0.482^{\mathrm{c}}$ & $6.54 \pm 0.0436^{\mathrm{b}}$ & $0.199 \pm 0.0290^{\mathrm{c}}$ \\
DF-6 & $1.908 \pm 0.243^{\mathrm{c}}$ & $0.289 \pm 0.432^{\mathrm{b}, \mathrm{c}}$ & $6.43 \pm 0.0400^{\mathrm{d}}$ & $0.211 \pm 0.0202^{\mathrm{b}, \mathrm{c}}$ \\
DF-9 & $2.316 \pm 0.271^{\mathrm{b}}$ & $0.318 \pm 0.410^{\mathrm{a}, \mathrm{b}}$ & $6.32 \pm 0.0473^{\mathrm{e}}$ & $0.254 \pm 0.0090^{\mathrm{b}}$ \\
DF-12 & $1.878 \pm 0.258^{\mathrm{c}}$ & $0.327 \pm 0.426^{\mathrm{a}}$ & $6.18 \pm 0.0322^{\mathrm{f}}$ & $0.229 \pm 0.0104^{\mathrm{b}, \mathrm{c}}$ \\
DF-15 & $1.748 \pm 0.261^{\mathrm{c}}$ & $0.348 \pm 0.415^{\mathrm{a}}$ & $0.179 \pm 0.0351^{\mathrm{c}}$
\end{tabular}

${ }^{a}$ All the values are the mean \pm SD. Values with different letters within a column are significantly different at $p<0.05$ as evaluated by Tukey's test to analyze the different soybean DF contents and the CK (a natural rice) in the same column.

\subsection{Changes in the FTIR spectra of the extruded rice with different levels of DF}

FTIR is sensitive to the structural changes on a short-range molecular level. The FTIR spectra of different DF levels in extruded rice grains are presented in Fig. 3. All six extruded rice samples had very similar FTIR spectra with peaks located in the same wavenumber ranges (Fig. 3) with an $\mathrm{O}-\mathrm{H}$ stretching vibration at $3600-320 \mathrm{~cm}^{-1}$ and a $\mathrm{C}-\mathrm{O}$ stretching vibration for $-\mathrm{CHO}$ at $1127 \mathrm{~cm}^{-1}$, indicating that there are more hydroxide radicals and water molecules in the molecule. There is a strong absorption peak for $-\mathrm{COOR}$ or $-\mathrm{CHO}$ in the $\mathrm{C}=\mathrm{O}$ bond stretching vibration at $1639 \mathrm{~cm}^{-1}$. For the $1420-1320 \mathrm{~cm}^{-1}$ wide absorption peak, a shoulder is present representing the $-\mathrm{COOR}$ in the $\mathrm{C}-\mathrm{O}$ stretching vibration. A C-N stretching vibration peak is present at $1385 \mathrm{~cm}^{-1}$, which may be from the carbonyl group or ethanoyl group of the protein or from lipid telescopic vibration. Two small absorption peaks at $600-700 \mathrm{~cm}^{-1}$ are the secondary amide IV and $\mathrm{V}$ peaks, indicating the presence of a secondary amide in the molecule. The results showed that high DF levels in extruded rice grain resulted in wide peak shapes, likely due to intramolecular glycosidic bond breakage that resulted in an increase in the number of free-OH groups, leading to stronger physicochemical properties. Similar nonsignificant differences between the FTIR for raw and extruded protein-maltodextrin mixtures were previously reported..$^{\mathbf{1 0 , 4 7}}$

\subsection{Dietary fiber of cooked extruded rice grain}

The effects of extrusion on the TDF and SDF contents of extruded rice grain with different DF levels are presented in
Fig. 4. The TDF content increased gradually as the DF content increased, and the TDF content of extruded rice with DF-12 reached $0.105 \pm 0.013 \mathrm{~g} \mathrm{~g}^{-1}$ (Fig. 4A). The extruded rice with DT-9 showed a significantly different SDF content from the other samples and had the highest SDF content $(0.042 \pm 0.002 \mathrm{~g}$ $\mathrm{g}^{-1}$ ) (Fig. 4B). Consistent with previous observations, extrusion improves the functionality of SDF. ${ }^{22,48,49}$

\subsection{Starch digestibility in vitro and glycemic index (GI)}

The enzymatically assessed RDS, SDS and RS contents of extruded rice with different DF levels and their GI are shown in

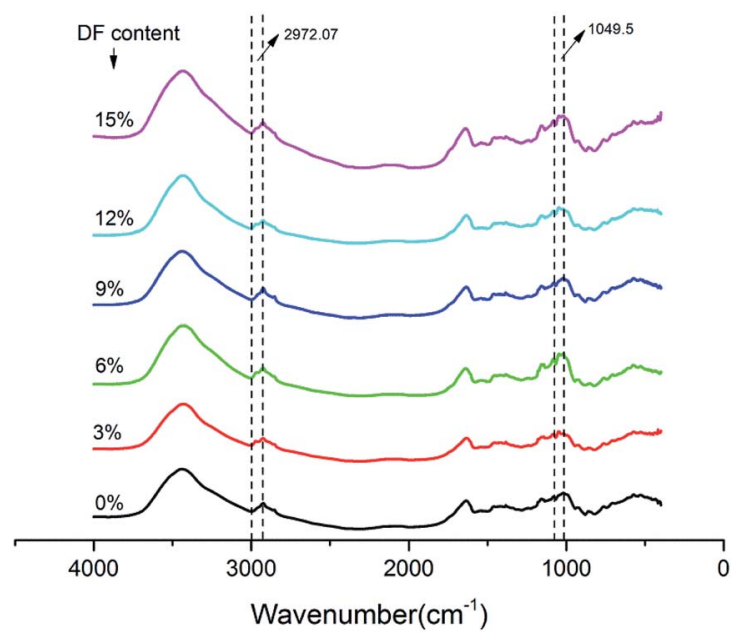

Fig. 3 FTIR spectra of extruded rice grain with different DF levels. 
Fig. 5. Fig. 5A shows that the extruded rice with a higher DF addition contained significantly lower RDS, which reduced the readily and completely digested fraction in the small intestine and expressed lower postprandial plasma glucose. At a DF addition of $3 \%$, RDS reached the maximum (84.519 $\mathrm{mg} \mathrm{g}^{-1}$ ), and RS was at the minimum (11.046 $\left.\mathrm{mg} \mathrm{g}^{-1}\right)$. This finding was observed due to a combination of two effects; one effect, consistent with previous studies, showed that the extrusion process treatments increased the RDS content due to the destruction of the double helix structure inside the starch granules during processing. ${ }^{\mathbf{5 0 , 5 1}}$ Another effect was consistent with the hypothesis that dietary fiber reduced the RDS content because a fraction of RDS starch was embedded in the DF, and as resistant starch RS1, DF can affect the digestion and absorption of starch..$^{52}$

Ingestion of SDS content slows and prolongs the postprandial release of glucose compared to those of RDS. SDS has the potential to modulate the body's glycemic response and enhances the nutritional profile of foods by increasing the amount of SDS in diabetic patients. ${ }^{53,54}$ The SDS content was observed to be highest for DF-9 extruded rice due to the increased steric hindrance of starch due to the introduction of fiber macromolecules, thus delaying the interaction between the enzyme and starch at the internal point of contact (Fig. 5B).$^{55}$ In addition to SDS, the RS contents of extruded rice with a higher amount of DF added were
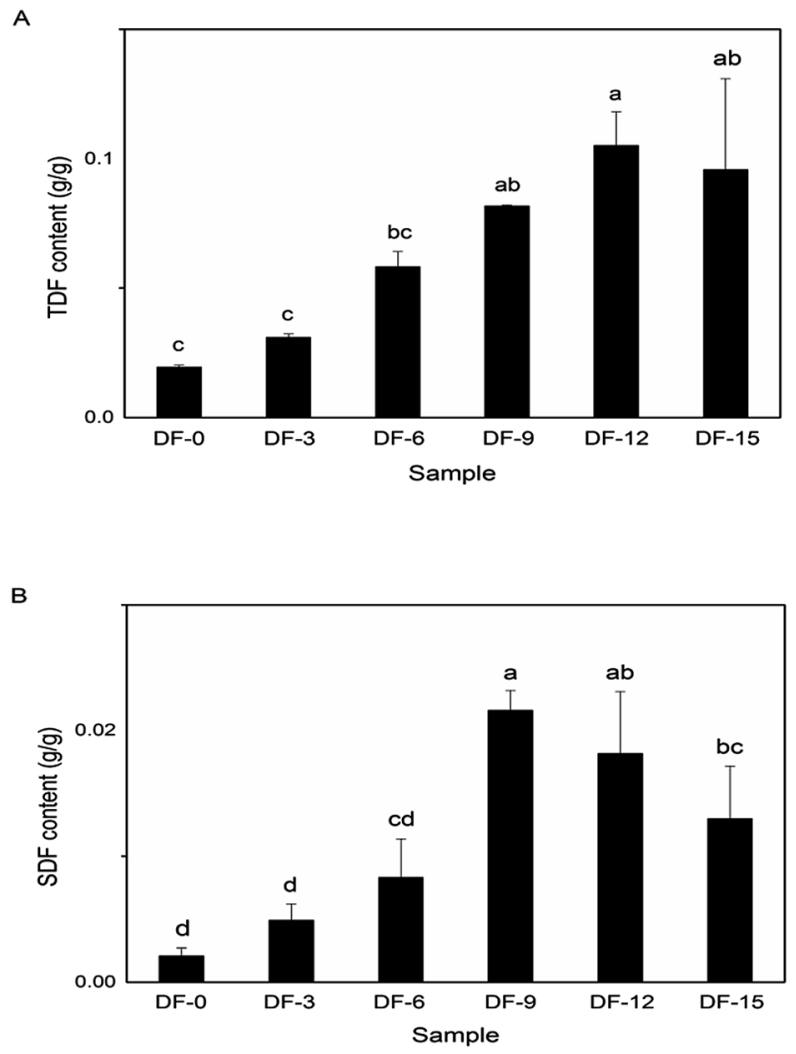

Fig. 4 Dietary fiber content of extruded rice grain with different DF levels. (A) TDF content of extruded rice with different DF levels; (B) SDF content of extruded rice with different DF levels. All the values are mean $\pm S D$. Columns with different letters are significantly different at $p<0.05$ as evaluated by Tukey's test to analyze the different soybean DF contents and the CK (a natural rice) in the same column.
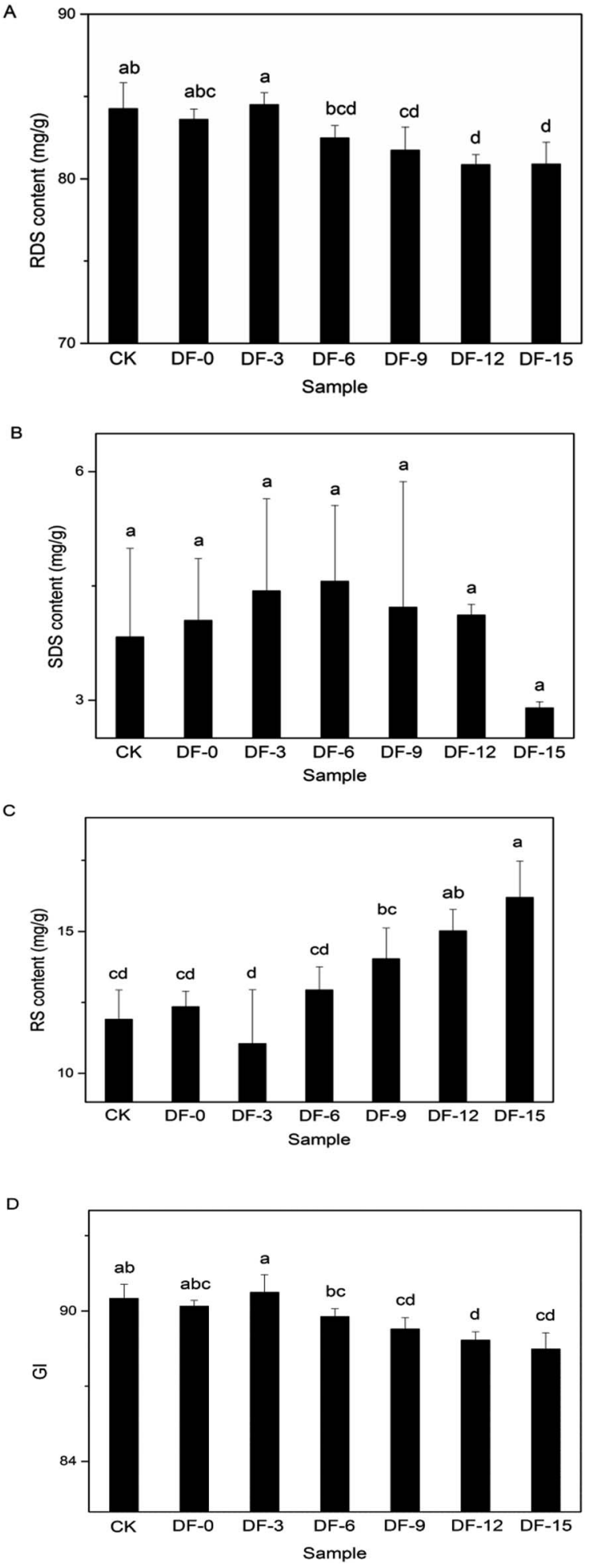

Fig. 5 Effect of DF content on starch digestibility in vitro and the Gl of extruded rice grain. (A) RDS content of extruded rice with different DF additions; (B) SDS content of extruded rice with different DF additions; (C) RS content of extruded rice with different DF additions; (D) Gl change in extruded rice with different DF additions. All the values are the mean $\pm S D$. Columns with different letters are significantly different at $p<0.05$ as evaluated by Tukey's test to analyze the different soybean DF contents and the CK (a natural rice) in the same column. 
significantly higher, at $14.041 \mathrm{mg} \mathrm{g}^{-1}, 15.023 \mathrm{mg} \mathrm{g}^{-1}$ and $16.197 \mathrm{mg} \mathrm{g}^{-1}$ in DF-9, DF-12 and DF-15, respectively (Fig. 5C). The increase observed for higher DF extruded rice contributed to lower starch digestibility.

GI is an indicator of how food causes the postprandial blood glucose response in biological systems and indicates the physiological parameters of that food. GI is a comparative value reflecting the speed and ability of food to increase blood glucose compared to glucose, which is normalized to 100 . The GI values of extruded rice and natural CK rice are shown in Fig. 5D. DF addition resulted in a significantly lower GI when the DF addition level reached $9 \%$, which was consistent with the results in which the RDS was reduced and the RS was increased; these findings agree with previous reports that high dietary fiber intake is often correlated with low dietary GI. ${ }^{56}$ This phenomenon may be because the SDF significantly increased during the extrusion process, and the SDF blocked the binding of starch granules with water, thus preventing starch pasting and ultimately affecting digestion. Thus, fortification of rice with $>6 \%$ DF would be highly beneficial for chronic diseases because of the regulation of carbohydrate digestion, which is especially helpful in the diets of diabetic and obese patients and patients suffering from cardiovascular diseases.

\section{Conclusions}

In this study, a low-cost, nutritious and high dietary fiber extruded staple rice was reported. The effects of different levels of soybean dietary fiber on the physicochemical, pasting, taste, palatability, cooking and starch digestibility properties of fiber and protein fortified rice grain were analyzed. The extruded rice had a similar density to that of natural rice and a significantly lower whiteness degree and transparency with increasing DF levels. Notably, the texture and palatability of extruded rice was very good, especially in DF 6-9\% (w/w) samples, which had a taste value close to 70 . The results revealed that the pasting properties, microstructure, and molecular interactions examined by RVA, SEM and FTIR, respectively, were significantly affected by the DF content. Importantly, starch digestibility in vitro showed significantly lower RDS and higher RS in DF $6-15 \%(w / w)$ than in natural and DF-0 rice, respectively. The GI was evidently reduced in DF $>6 \%$, possibly because of the increase in SDF in higher DF extruded rice $\left(0.0021 \mathrm{~g} \mathrm{~g}^{-1}\right.$ to $\left.0.216 \mathrm{~g} \mathrm{~g}^{-1}\right)$. Here, we provide a new higher dietary fiber extruded rice product with good texture and palatability, and we revealed the effect of DF on the extruded rice properties. All the results provide insights for the development of more functional staple foods using the dry flour extrusion processing technique.

\section{Conflicts of interest}

The authors declare that there are no conflicts of interest.

\section{Acknowledgements}

This work was supported by grants from the 123 Industry Integration Development Science and Technology Demonstration Project and Science and Technology Project of Tianjin (17ZXYENC00160, 16ZXZYNC00110 and 14RCGFNC00102).

\section{References}

1 M. Shimabukuro, M. Higa, R. Kinjo, K. Yamakawa, H. Tanaka, C. Kozuka, K. Yabiku, S. Taira, M. Sata and H. Masuzaki, Br. J. Nutr., 2014, 111, 310-320.

2 S. P. Whelton, A. D. Hyre, B. Pedersen, Y. Yi, P. K. Whelton and J. He, J. Hypertens., 2005, 23, 475-481.

3 D. Lairon, N. Arnault, S. Bertrais, R. Planells, E. Clero, S. Hercberg and M. C. Boutron-Ruault, Am. J. Clin. Nutr., 2005, 82, 1185-1194.

4 M. M. Kaczmarczyk, M. J. Miller and G. G. Freund, Metabolism, 2012, 61, 1058-1066.

5 H. C. Simpson, R. W. Simpson, S. Lousley, R. D. Carter, M. Geekie, T. D. Hockaday and J. I. Mann, Lancet, 1981, 1, 1-5. 6 A. Satija and F. B. Hu, Curr. Atheroscler. Rep., 2012, 14, 505514.

7 J. W. Anderson, P. Baird, R. H. Davis Jr, S. Ferreri, M. Knudtson, A. Koraym, V. Waters and C. L. Williams, Nutr. Rev., 2009, 67, 188-205.

8 N. K. Fageria, J. Plant Nutr., 2007, 30, 843-879.

9 E. Xu, Z. Wu, J. Long, F. Wang, X. Xu, Z. Jin and A. Jiao, J. Funct. Foods, 2015, 17, 214-226.

10 E. Xu, Z. Wu, X. Pan, J. Long, F. Wang, X. Xu, Z. Jin and A. Jiao, Food Chem., 2016, 197, 114-123.

11 C. Philipp, I. Oey, P. Silcock, S. M. Beck and R. Buckow, J. Food Eng., 2017, 212, 165-173.

12 R. P. Rathod and U. S. Annapure, LWT-Food Sci. Technol., 2017, 80, 121-130.

13 M. Ciudad-Mulero, L. Barros, A. Fernandes, J. D. J. Berrios, M. Camara, P. Morales, V. Fernandez-Ruiz and I. C. F. R. Ferreira, Food Funct., 2018, 9, 819-829.

14 A. Wojtowicz, M. Zalewska-Korona, E. Jablonska-Rys, K. Skalicka-Wozniak and A. Oniszczuk, Pol. J. Food Nutr. Sci., 2018, 68, 251-261.

15 R. Kumar, K. A. M. Xavier, M. Lekshmi, V. Dhanabalan, M. T. Thachil, A. K. Balange and V. Gudipati, J. Sci. Food Agric., 2018, 98, 2393-2401.

16 R. Gopirajah and K. Muthukumarappan, J. Food Process. Preserv., 2018, 42.

17 J. Li, A. Jiao, M. M. A. Rashed, L. Deng, X. Xu and Z. Jin, J. Food Sci., 2018, 83, 332-339.

18 L. Roman, J. Pico, B. Antolin, M. M. Martinez and M. Gomez, Food Chem., 2018, 260, 106-114.

19 P. Rani, A. Kumar, S. R. Purohit and P. S. Rao, LWT-Food Sci. Technol., 2018, 89, 155-163.

20 R. Kumari, V. Abhishek and M. Gupta,J. Food Meas. Charact., 2018, 12, 1219-1228.

21 M. Zhang, X. Bai and Z. Zhang, J. Cereal Sci., 2011, 54, 98103. 
22 Y. Chen, R. Ye, L. Yin and N. Zhang, J. Food Eng., 2014, 120, 1-8.

23 V. Tejada-Ortigoza, L. Eduardo Garcia-Amezquita, S. O. Serna-Saldivar and J. Welti-Chanes, Food Eng. Rev., 2016, 8, 251-271.

24 R. J. Bryant, R. S. Kadan, E. T. Champagne, B. T. Vinyard and D. Boykin, Cereal Chem., 2001, 78, 131-137.

25 R. Tahvonen, A. Hietanen, T. Sankelo, V. M. Korteniemi, P. Laakso and H. Kallio, Z. Lebensm.-Unters. -Forsch. A, 1998, 206, 360-363.

26 A. A. Anton, R. G. Fulcher and S. D. Arntfield, Food Chem., 2009, 113, 989-996.

27 N. Nikmaram, S. Y. Leong, M. Koubaa, Z. Zhu, F. J. Barba, R. Greiner, I. Oey and S. Roohinejad, Food Control, 2017, 79, 62-73.

28 M. S. Alam, J. Kaur, H. Khaira and K. Gupta, Crit. Rev. Food Sci. Nutr., 2016, 56, 445-473.

29 H. Chanvrier, S. Uthayakumaran and P. Lillford, J. Cereal Sci., 2007, 45, 263-274.

30 L. Alvarez Martinez, K. P. Kondury and J. M. Harper, J. Food Sci., 2010, 53, 609-615.

31 S. Chaiyakul, K. Jangchud, A. Jangchud, P. Wuttijumnong and R. Winger, LWT-Food Sci. Technol., 2009, 42, 781-787.

32 E. T. Champagne, K. L. Bett, B. T. Vinyard, A. M. McClung, F. E. Barton, K. Moldenhauer, S. Linscombe and K. McKenzie, Cereal Chem., 1999, 76, 764-771.

33 S. C. Lai, M. Kawano, Z. D. Wang, T. Mikami, D. Q. Huang, L. I. Hong, L. U. De-Cheng, D. G. Zhou and S. C. Zhou, Chin. J. Rice Sci., 2011, 25(4), 435-438.

34 Y. Chen, R. Ye and J. Liu, Ind. Crops Prod., 2014, 53, 140-147.

35 H. N. Englyst, S. M. Kingman and J. H. Cummings, Eur. J. Clin. Nutr., 1992, 46(suppl. 2), S33-S50.

36 K. S. Sandhu and S. Lim, Carbohydr. Polym., 2008, 71, 245252.

37 I. Goñi, A. Garcia-Alonso and F. Saura-Calixto, Nutr. Res., 1997, 17, 427-437.

38 Y. Granfeldt, I. Bjorck, A. Drews and J. Tovar, Eur. J. Clin. Nutr., 1992, 46, 649-660.
39 M. Wen, X. Li, L. Xia, X. Jia, Z. Hua and Z. Li, J. Chin. Inst. Food Sci. Technol., 2014, 14, 42-48.

40 C. Philipp, R. Buckow, P. Silcock and I. Oey, Food Res. Int., 2017, 102, 658-665.

41 W. H. Wang, Food \& Machinery, 2011, 27, 14-16.

$42 \mathrm{X}$. Zhang, L. Shi, D. Ding, S. Wang and J. Cui, Chinese Agricultural Science Bulletin, 2010, 26(12), 45-47.

43 M. A. Fitzgerald, M. Martin, R. M. Ward, W. D. Park and H. J. Shead, J. Agric. Food Chem., 2003, 51, 2295-2299.

44 J. C. T. Concepcion, S. Ouk, A. Riedel, M. Calingacion, D. Zhao, M. Ouk, M. J. Garson and M. A. Fitzgerald, Food Chem., 2018, 240, 1014-1021.

45 L. C. Oliveira, C. M. Rosell and C. J. Steel, Int. J. Food Sci. Technol., 2015, 50, 1504-1514.

46 F. Figuerola, M. L. Hurtado, A. M. Estevez, I. Chiffelle and F. Asenjo, Food Chem., 2005, 91, 395-401.

47 V. P. Yuryev, D. V. Zasypkin, Y. V. Ghenin, V. A. Zhukov, V. V. Alexeyev and V. B. Tolstoguzov, Carbohydr. Polym., 1991, 15, 243-253.

48 H. Li, D. Long, J. Peng, M. Jian and G. Zhao, Innovative Food Sci. Emerging Technol., 2012, 16, 80-88.

49 A. Gao, X. Yan, X. Xu, R. Ye and Y. Chen, Food Bioprocess Technol., 2015, 8, 2036-2046.

50 M. Kaur, K. S. Sandhu, R. P. Ahlawat and S. Sharma, J. Food Sci. Technol., 2015, 52, 1642.

51 X. Chen, X. He, X. Fu, B. Zhang and Q. Huang, Int. J. Biol. Macromol., 2017, 98, 557-564.

52 H. J. Chung, Q. Liu and R. Hoover, Carbohydr. Polym., 2009, 75, 436-447.

53 M. M. Grundy, C. H. Edwards, A. R. Mackie, M. J. Gidley, P. J. Butterworth and P. R. Ellis, Br. J. Nutr., 2016, 116, 816-833.

54 S. Vinoy, A. Meynier, A. Goux, N. Jourdan-Salloum, S. Normand, R. Rabasa-Lhoret, O. Brack, J. Nazare, F. Peronnet and M. Laville, Nutrients, 2017, 9, 318.

55 Z. Lu, E. Donner and Q. Liu, Food Chem., 2018, 245, 71-78. 56 M. Schulz, A. D. Liese, E. J. Mayer-Davis, R. B. D'Agostino, F. Fang, K. C. Sparks and T. M. Wolever, Br. J. Nutr., 2005, 94, 397-406. 